\title{
Emoções e trabalho: estudo sobre a influência do status e do sexo na atribuição de afetos
}

\author{
Sônia Maria Guedes Gondim ${ }^{\mathrm{I}, 1}$, José Luis Alvaro Estramiana ${ }^{\mathrm{II}, 2}$, \\ André de Figueiredo Luna, ${ }^{\mathrm{I}, 3}$, Graceane Coelho de Souza, ${ }^{\mathrm{I}, 4}$, Louise \\ Cristine Santos Sobral ${ }^{1,5}$ e Claudia Carla de Azevedo Brunelli Rego ${ }^{6}$ \\ ${ }^{\mathrm{I}}$ Universidade Federal da Bahia \\ ${ }^{\text {II }}$ Universidad Complutense de Madrid
}

\begin{abstract}
O estudo explorou as atribuições de emoções a supervisores e empregados em interação de trabalho em três países distintos. A fundamentação teórica apoiou-se na abordagem interacional social das emoções de Kemper e nos estudos de Algoe, Buswell e Delamater. Participaram 238 pessoas: 100 da Espanha, 38 da Inglaterra e 100 do Brasil, sendo 73 homens e 158 mulheres (7 não identificaram o sexo). O objetivo foi investigar se informações de status (supervisor ou empregado) e sexo (homem ou mulher) dos atores influenciavam nas atribuições de emoções a supervisores e empregados e se variavam conforme país e experiência de trabalho. Foram utilizadas 4 condições experimentais, variando sexo e status. Estudos anteriores concluíram que o status exerce maior influência que o sexo nas atribuições de emoções em interações de trabalho. Os resultados do presente estudo sinalizam que a interação no trabalho é percebida nos três países como harmoniosa, embora as atribuições de emoções positivas aos supervisores tenham sido mais frequentes, o que revela a importância do status profissional. Mulheres atribuíram mais afetos negativos à interação no trabalho do que os homens. A expressão facial de tristeza foi a mais relacionada a supervisores e empregados, embora para supervisores estivesse associada à seriedade e ao distanciamento emocional.
\end{abstract}

Palavras-chave: Emoções no trabalho, Atribuições de afetos, Pesquisa intercultural.

Emotions and work: study about the influences of status and sex in the attribution of affects

This study investigated the emotions attributed to supervisors and employees involved in a work interaction in three different countries This research is based on Kemper's social interactional theory of emotions and the Algoe, Buswell and DeLamaters' studies. 238 people participated in this study: 100 were from Spain, 38 from England and 100 were from Brazil. From the total, 73 were male and 158 female ( 7 did not respond). The goal was to investigate whether the emotions attributed to supervisors and employees are influenced by information of professional status (employee or supervisor) and actor's sex (male or female). Also, whether the emotions attributed varied according to country and work experience. Four experimental conditions were created, they varied in sex and professional status. Previous studies concluded that professional status has more impact than sex on the attribution of emotions in the work place. The results of this study indicate that interaction at work is perceived as harmonious by participants from all three countries. However, positive emotions were attributed to supervisors more frequently - that shows the importance of professional status. Women attributed more negative emotions than men. The facial expression of sadness was the most chosen for employees and supervisors, although in this last case it was interpreted as expression of seriousness and emotional detachment.

Keywords: Emotions at workplace, Affects attributions, Intercultural research.

1 Professora Associada da Universidade Federal da Bahia. Instituto de Psicologia, Núcleo de Pós-graduação em Administração, Centro Interdisciplinar de Desenvolvimento e Gestão Social da Universidade Federal da Bahia. Doutora em Psicologia. Pósdoutorado na Universidade Complutense de Madrid e no Magdalene College da Cambridge University.

2 Catedrático de Psicologia Social no Departamento de Psicologia Social da Universidad Complutense de Madrid.

3 Estudante de Graduação em Psicologia da UFBA. Ex-bolsista de Iniciação Científica FAPESB/PIBIC-UFBA.

4 Psicóloga pela UFBA. Ex-bolsista de Iniciação Científica CNPq/PIBIC-UFBA.

5 Mestre em Psicologia pela UFBA. Ex-bolsista FAPESB.

6 Mestre em Desenvolvimento Humano e Responsabilidade Social pela Fundação Visconde de Cairu (Salvador, BA). 


\section{Introdução}

A s últimas décadas têm revelado notável avanço no conhecimento das emoções e de suas relações com a cognição (Bless, 2000; Davidson, Scherer \& Goldsmith, 2003; Ledoux, 1998; Lewis \& Haviland-Jones, 2004; Phelps, 2006). Esses estudos também reafirmam que as emoções são fundamentais na regulação das interações sociais (Barbalet, 2002; Burkitt, 2002; Oatley, Keltner \& Jenkins, 2007; Parkinson, Fischer \& Manstead, 2005; Turner \& Stets, 2005) e das relações de trabalho (Brief \& Weiss, 2002; Briner, 1999; Cobêro, Primi \& Muniz, 2006; Fineman, 1993; Grandey, 2000; Härtel, Zerbe \& Ashkanasy, 2004; Hochschild, 1979; Pekrun \& Frese, 1992; Totterdell \& Holman, 2003). Outros estudos têm apontado que as expressões emocionais faciais cumprem um papel fundamental no desenvolvimento e na regulação das relações humanas (Algoe et al., 2000; Ekman, 1999; Forgas \& George, 2001; Johnstone \& Scherer, 2004).

A constatação do avanço dos estudos sobre o tema das emoções não conseguiu dirimir, a contento, as divergências de entendimento dos estados afetivos e, embora esse não seja o propósito deste artigo, tal demarcação é relevante para a compreensão de como esse fenômeno foi aqui pesquisado. $\mathrm{O}$ reconhecimento de que existem controvérsias entre os especialistas torna desafiadora a tarefa de demarcar os conceitos de emoções, sentimentos e afetos, pois, além de esses fenômenos mostrarem-se inter-relacionados, a revisão de literatura sobre o assunto deixa transparecer a diversidade de tendências teórico-metodológicas existentes (Evans, 2003).

Na concepção cognitiva de Clore (Ortony, Clore \& Collins, 1990), cujo centro do interesse recai no que causa as emoções e as faz variar em intensidade, elas são definidas como reações dotadas de valência (positiva ou negativa) e dirigidas a três classes distintas de alvos: a) eventos e suas consequências; b) agentes ou atores sociais e suas ações e c) objetos propriamente ditos. Gray e Watson (2001), embora admitam a inter-relação de todos esses conceitos, demarcam as diferenças entre emoção, humor e afeto. $O$ afeto é a integração de emoções e humores, que, por sua vez, distinguem-se pelo tempo de duração e objeto a ser focado. Em termos de tempo de duração, a emoção é reativa, mantendo-se apenas por alguns segundos, além de estar focada em um objeto específico, enquanto o humor perdura por um período de minutos a dias e tem como alvo vários objetos simultâneos.

Apesar das diferenças encontradas na literatura, há relativo consenso de que a emoção é um estado afetivo ativado por processos neurofisiológicos que preparam o organismo para a ação (dimensão biológica), o que parece ter sido decisivo para o desenvolvimento da espécie humana. A história reúne fortes evidências de que as expressões faciais emocionais ajudaram aos homens a manter seus inimigos distantes (raiva), a aproximar os próprios pares para se reproduzirem (alegria), correr do perigo (medo), esquivar-se de situações aversivas (nojo) e chamar a atenção dos demais sobre os estados pessoais internos (tristeza).

Os sentimentos, distintamente das emoções, estas mais automáticas, referem-se a estados afetivos da dimensão subjetiva e cognitiva. Aqui, o que está em jogo é a experiência pessoal revelada no modo como a pessoa percebe os estados afetivos e os comunica aos demais, o que lhe permite a autorreflexão e a reavaliação de eventos emocionais automáticos. Além da dimensão biológica e evolutiva (emoção) e também da dimensão subjetiva (sentimentos), os estados afetivos - categoria mais ampla, que abarca emoções e sentimentos - possuem uma dimensão social, visto serem governados por regras compartilhadas, que influenciam a intensidade com que eles devem ser sentidos, a situação a que devem ser dirigidos e sua duração. Todavia, a avaliação de um sentimento como apropriado a um contexto, além de levar em conta a situação (social), considera o que a pessoa está sentindo, o que ela pensa sentir e o que faz sobre o que sente (dimensão subjetiva). Ademais, as expressões emocionais nem sempre são consensuais, o que historicamente faz emergir conflitos nas interações 
humanas. A interpretação equivocada da emoção alheia traz consequências para a qualidade da interação estabelecida entre os atores. Isso é um sinal de que os estados afetivos são complexos e abarcam dimensões variadas: biológica, subjetiva e social. A abordagem neurofisiológica explica como as emoções são estimuladas e expressas, mas é insuficiente para dar conta do que ocorre com os estados afetivos (dimensão subjetiva) no contexto das interações sociais em que estão em jogo os sentimentos (Gondim \& Alvaro, 2010).

Dada a importância das emoções e dos sentimentos na qualidade das interações humanas nos diversos contextos sociais e de trabalho, e também da aceitação da premissa de que há variedade na maneira como as emoções e sentimentos alheios são interpretados, tornase relevante estudar as atribuições de estados afetivos (emoções e sentimentos). Em outras palavras, a maneira como as emoções são interpretadas interferem na qualidade dos relacionamentos que estabelecemos socialmente com nítidas consequências para a emergência de conflitos, principalmente, no ambiente de trabalho, o que torna oportuno estudar os processos de atribuição de emoções.

\section{A pesquisa}

A pesquisa aqui relatada teve o objetivo de explorar a forma como são atribuídos emoções e afetos no ambiente organizacional, pois a suposição é a de que a qualidade da relação interpessoal no ambiente de trabalho é afetada pelo modo como tais atribuições são feitas. O estudo fez uma comparação entre três países - Espanha, Inglaterra e Brasil - no que tange às atribuições de emoções e sentimentos a supervisores e empregados. O presente estudo não fornece subsídios para concluir que o perfil atribuicional apresentado por brasileiros, espanhóis e ingleses, individualmente, representa o perfil médio de atribuições das culturas daqueles três países nos quais são residentes. Desse modo, a presença de diferenças significativas entre as respostas dos participantes dos três países apenas indica tendências de atribuição que precisam ser mais bem investigadas em estudos posteriores que explorem a contento variáveis interculturais.

A atribuição é um processo cognitivo e interpessoal de interpretação, que envolve percepção e julgamento por meio de inferência social e tem como objetivo dar sentido ao comportamento de outras pessoas. A importância desse processo decorre das consequências comportamentais que nele estão envolvidas (Crittenden, 1983). A atribuição de emoções parte da observação do comportamento do outro, sobretudo de suas expressões emocionais faciais (Caroll \& Russell, 1996), cumprindo, assim, um papel fundamental no desenvolvimento e na regulação das relações humanas (Algoe et al., 2000; Ekman, 1999). Se, por exemplo, o sorriso no rosto do supervisor favorece a aproximação do empregado, sinais de raiva contribuem para o seu afastamento. Tais expressões faciais, não obstante, são ambíguas, levando as pessoas a interpretarem as emoções e os sentimentos alheios com base nas informações de contexto status profissional e sexo (Algoe et al., 2000). Ou seja, a expressão de emoções é constituída por mensagens ambivalentes, cuja forma e significados podem ser modificados no contexto social da interação (Hess \& Kirouac, 2004). A importância da dimensão social na manifestação das emoções é compartilhada por Leary (2000), para quem é no contexto das interações humanas que as emoções sociais se manifestam. Tais emoções oferecem subsídio para se avaliar uma interação social como positiva ou negativa. No primeiro caso, percebe-se troca de afetos positivos entre os dois atores na interação, e, no segundo, predominam os afetos negativos.

A teoria interacional social das emoções de Kemper $(1978,2004)$ é mais precisa na demarcação da dimensão social das emoções. Para o autor, elas estão relacionadas à percepção de status e de poder dos atores em interação. No contexto da pesquisa aqui relatada, o fato de a 
pessoa ser percebida como supervisor ou empregado, homem ou mulher, repercutiria nas atribuições das emoções feitas a esses atores.

Estudos anteriores, realizados tanto no Brasil (Lima, Gondim, Santos, Sá \& Bonfim, 2005) quanto na Espanha (Gondim, Alvaro, Schweiger Gallo, Sá \& Rios, 2008; Gondim, Lima $\&$ Alvaro, 2006), oferecem suporte empírico para a tese de que as informações sobre status e sexo influenciam nas atribuições de emoções (emoções mais positivas para os supervisores do que para os empregados), assim como as experiências de trabalho em cada país. Embora brasileiros e espanhóis atribuam mais emoções positivas aos supervisores do que aos empregados, a percepção de status e poder do supervisor repercute, de modo distinto, nas atribuições de emoções. Isso significa que, apesar da tendência geral de se atribuírem emoções positivas a quem tem mais status, a experiência de trabalho de espanhóis e brasileiros parece ser distinta, pois os primeiros identificam-se mais com o empregado e os últimos, com o supervisor. Em síntese, os espanhóis que trabalham tendem a se identificar com o empregado, compreender sua condição e, em decorrência disso, atribuir-lhe menos emoções negativas (medo e insegurança) do que os brasileiros. Os brasileiros que trabalham, ao contrário, identificam-se com o supervisor, atribuindo-lhe mais emoções positivas do que os espanhóis.

Ao dar continuidade a essa linha de investigação científica sobre atribuições de emoções em contextos de trabalho, a pesquisa atual investigou se as variáveis status e poder (na perspectiva de Kemper) e o sexo exerceriam influência nas atribuições de emoções, independentemente de serem países com culturas distintas e das experiências de trabalho em cada um deles, tal como encontrado em estudos anteriores. $\mathrm{O}$ entendimento é que o processo de socialização particular a cada cultura e país influencia na eleição das emoções a serem expressas, além de delimitar quando, onde, em que grau e por que razão determinado padrão emocional seria escolhido em detrimento de outro (Kemper, 2004).

Em resumo, a pesquisa procurou analisar se as dicas situacionais (informações de contexto sobre sexo e status) repercutem nas atribuições de emoções e sentimentos dos atores sociais. $\mathrm{O}$ entendimento é que as atribuições emocionais a supervisores e empregados ajudam a minimizar ou acirrar tensões nas interações de trabalho. Desse modo, emoções e cognições estão implicadas na qualidade dessas interações.

As questões de pesquisa podem ser assim resumidas: a) independentemente do país, atribuem-se mais emoções positivas ao supervisor que ao empregado? b) a experiência de trabalho como supervisor ou empregado em cada país influencia nas atribuições de emoções a supervisores e empregados? c) informações do sexo e status (poder) profissional (supervisor ou empregado) influenciam nas atribuições a esses atores?

Tais questões encontram suporte nas teorias atribuicionais (Caroll \& Russell, 1996; Crittenden, 1983), nos estudos de Algoe et al. (2000) sobre a influência de dicas de contexto em processos de atribuição e na teoria interacional social das emoções de Kemper (1978, 2004). A experiência de trabalho foi incluída na pesquisa, por se acreditar que a construção de significados relacionais e a forma de entender a dinâmica interpessoal são aprendidas em contextos de socialização e influenciam na identificação com o outro, com suas ações e também suas expressões emocionais.

Por fim, julgou-se importante avaliar o sexo, por sua relevância na formação de juízos sociais (Eagly, Mackhijani \& Klonsky, 1992). A ampla revisão de literatura de Brody e Hall (1993) sobre o papel das emoções na diferenciação social leva a concluir a favor da existência da crença compartilhada de que homens e mulheres, ao assumirem papéis masculinos e femininos nas interações sociais, expressam emoções distintas (Algoe, et al., 2000; Fischer \& Manstead, 2000; Plant, Hyde, Keltner \& Devine, 2000). 


\section{O método}

\section{Participantes}

Participaram da pesquisa 238 pessoas, sendo 100 da Espanha, 38 da Inglaterra e 100 do Brasil. Desses participantes, 73 eram do sexo masculino e 158 do feminino (sete pessoas não mencionaram o sexo). O número reduzido de participantes da Inglaterra decorreu do curto período de coleta nesse país e da dificuldade de obter adesão dos nativos, dado seu caráter voluntário, sem nenhum tipo de recompensa financeira ou de créditos em disciplinas curriculares. A idade variou entre 18 e 60 anos $(M=30,20 ; d p=10,88)$. A grande parte da amostra pesquisada (96\%) trabalhava ou havia trabalhado. 158 pessoas $(68,7 \%)$ tiveram experiência como supervisores e 218 (94,8\%) como empregados. Não foram explorados alguns dados sociodemográficos dos participantes, como por exemplo, remuneração, em virtude das dificuldades posteriores de estabelecer comparabilidade entre os três países. No Brasil, os participantes eram estudantes de ensino superior de cursos noturnos de uma faculdade particular do nordeste do país. Na Espanha (Madri) e na Inglaterra (Cambridge), os participantes foram convidados a participar mediante uma lista de e-mail de instituições de ensino superior. Horários foram marcados para aplicação dos instrumentos em salas designadas para esse fim nas respectivas instituições de ensino superior de cada país.

\section{Desenho}

O estudo foi composto por quatro grupos experimentais, organizados por status (supervisor ou empregado) e sexo, cujos participantes foram distribuídos de modo aleatório. Consideramos ainda como variável independente o sexo e o país de origem. A atribuição de emoções e sentimentos (afetos) aos atores, nos papéis de supervisor e de empregado, constituiu a variável dependente. $\mathrm{O}$ Quadro 1 mostra a distribuição dos participantes por condição experimental e por país.

Quadro 1: Desenho do estudo e distribuição dos participantes por condição experimental e país

\begin{tabular}{|l|l|l|l|l|}
\hline \multirow{2}{*}{ Condição de resposta } & \multicolumn{3}{|c|}{ País de quem responde } & \multirow{2}{*}{ Total } \\
\cline { 2 - 5 } & Espanha & Inglaterra & Brasil & 58 \\
\hline 1) Supervisor homem e empregado homem & 25 & 10 & 23 & 66 \\
\hline 2) Supervisor homem e empregado mulher & 25 & 13 & 28 & 59 \\
\hline 3) Supervisor mulher e empregado homem & 25 & 8 & 26 & 55 \\
\hline 4) Supervisor mulher e empregado mulher & 25 & 7 & 23 & 238 \\
\hline Total & 100 & 38 & 100 & \\
\hline
\end{tabular}

\section{Preparação dos instrumentos e coleta de dados}

Os estados afetivos considerados na presente pesquisa, para investigar a atribuição de emoções aos atores e a qualidade (positiva ou negativa) da interação estabelecida entre eles, foram escolhidos com base nas respostas dos participantes à questão aberta de pesquisa anterior sobre o mesmo tema. A primeira versão do questionário foi elaborada em espanhol e, posteriormente, traduzida para o inglês e o português. Foram utilizados dois vídeos amadores de 
atores brasileiros: o primeiro simulava uma interação rotineira de trabalho (o supervisor orientava um empregado recém-admitido a como realizar seu trabalho) e o segundo exibia as expressões faciais emocionais básicas (Ekman, 1999) dos dois atores (raiva, tristeza, alegria, nojo e medo). Esse segundo vídeo exibia durante cinco segundos cada uma das cinco expressões faciais anteriormente referidas, como se o ator estivesse exibindo espontaneamente a emoção sugerida. Foram elaborados quatro vídeos que exibiam a interação, uma para cada condição experimental, e que foram posteriormente dublados para o espanhol e o inglês por nativos. Na Espanha e no Brasil, a coleta de dados foi feita por um dos pesquisadores com uma equipe de assistentes, enquanto que, na Inglaterra, foi feita por auxiliares de pesquisa nativos.

\section{Procedimentos e instrumentos}

Inicialmente, foi apresentado o primeiro vídeo de dois minutos e meio, que mostrava um pequeno diálogo no qual o supervisor orientava o empregado a realizar corretamente uma tarefa. A interação rotineira de trabalho retratada no vídeo acontecia em uma empresa de publicidade. Esse cenário foi escolhido porque nele a hierarquia é em geral menos demarcada, optando-se pela composição de equipes multidisciplinares de trabalho, como maior potencial para proporcionar maleabilidade e proximidade entre seus membros. Isso atenuaria um viés atribuicional decorrente de contexto organizacional marcadamente hierarquizado, distintamente de outros tipos de organizações que dão destaque à diferença de status profissional (Gatton, DuBois \& Faley, 1999).

Após a exibição desse vídeo, os participantes eram orientados a responder a primeira parte do questionário com duas questões. A primeira continha dois quadros para que $\mathrm{o}$ participante atribuísse intensidade às emoções e aos sentimentos percebidos em cada um dos dois atores, supervisor (quadro 1) e empregado (quadro 2). A escala variava de um a quatro pontos ( 1 =nada, 2 =pouco, $3=$ moderado, $4=$ muito $)$ e incluía as emoções e os sentimentos que os participantes julgavam estar sendo experimentadas pelos atores naquela relação de trabalho. Os quadros eram iguais para o supervisor e para o empregado e apresentavam uma sequência de dezesseis emoções e sentimentos, sendo oito considerados positivos (bem-estar, segurança, otimismo, autoconfiança, alegria, tranquilidade, autocontrole e bom humor) e oito negativos (ansiedade, medo, insatisfação, frieza, tristeza, raiva, desprazer e aborrecimento). Os dezesseis sentimentos e emoções foram escolhidos com base em resultados de pesquisas anteriores, em que os participantes eram convidados a nomear espontaneamente as emoções que observavam nos atores em interação.

A segunda parte incluía uma tabela com uma lista de vinte e sete características que estariam presentes na interação entre os profissionais, como, por exemplo, amizade, tolerância, pena e humilhação. O participante tinha a opção de assinalar, para cada característica definidora da qualidade (positiva ou negativa) da interação entre supervisor e empregado, se ela estava presente ou ausente na relação. Se o participante julgasse que ela estava presente, deveria indicar se ela partia do supervisor ou do empregado ou de ambos, qualificando, assim, a interação entre os profissionais que estava sendo exibida no vídeo.

Em seguida, os participantes eram arguidos sobre sua experiência como supervisor ou supervisionado e se conheciam alguém que tivesse passado por situação semelhante à apresentada no vídeo. Nesse último caso, o objetivo era avaliar se o vídeo estaria trazendo uma situação muito distante da realidade do participante, o que teria de ser considerado criticamente na análise das atribuições.

Após a conclusão dessa etapa, outro vídeo de um minuto e meio era apresentado, no qual o supervisor e o empregado, separadamente, exibiam as cinco expressões faciais básicas (tristeza, alegria, medo, raiva, nojo). Era solicitado aos participantes que escolhessem entre as cinco expressões a mais representativa para cada um dos atores do vídeo, em seus respectivos 
papéis de supervisor e empregado. Cada expressão exibida no vídeo era precedida da indicação "expressão 1" ou "expressão 2", respectivamente, até a quinta expressão, sem qualquer referência ao tipo de emoção. Depois de indicar qual daquelas expressões faciais correspondia às emoções do supervisor e do empregado, respectivamente, na interação de trabalho exibida anteriormente, os participantes davam um nome para aquela expressão emocional. Portanto, o que estava em jogo era a atribuição e não o reconhecimento de uma expressão emocional facial positiva ou negativa.

Por fim, o questionário continha uma seção para identificar a idade, o sexo e o país e se o participante estava trabalhando ou já havia trabalhado na ocasião da coleta de dados.

\section{Resultados e discussão}

Esta seção está dividida em três subseções. A primeira apresenta e discute os resultados das atribuições de afetos (emoções e sentimentos) a cada um dos atores em separado. A segunda seção faz o mesmo em relação às atribuições de afetos à interação entre o supervisor e o empregado. A terceira e última dedica-se à discussão dos resultados da escolha das expressões faciais representativas de cada um dos atores (supervisor e empregado) e as atribuições de afetos a elas relacionadas.

\section{Atribuição de emoções e sentimentos para supervisor e empregado}

Os estados afetivos foram reunidos em quatro grupos: a) emoções positivas do supervisor; b) emoções positivas do empregado; c) emoções negativas do supervisor; d) emoções negativas do empregado. Oito afetos ficaram no grupo das emoções positivas (bemestar, segurança, otimismo, autoconfiança, alegria, tranquilidade, autocontrole e bom humor), e oito ficaram no grupo das emoções negativas (ansiedade, medo, insatisfação, frieza, tristeza, raiva, desprazer e aborrecimento).

No Quadro 2, são apresentados os valores referentes às médias de atribuição das emoções (para fins de análise, emoções e afetos foram considerados sinônimos), os quais permitem constatar que foram atribuídas mais emoções positivas do que negativas, tanto para o supervisor, quanto para o empregado, em todos os países pesquisados.

Quadro 2: Média e desvio padrão das emoções positivas e negativas para supervisor e empregado por país

\begin{tabular}{|c|c|c|c|c|}
\hline & Espanha & Inglaterra & Brasil & Total $^{*}$ \\
\hline Emoções atribuídas & $\begin{array}{l}\text { M } \\
\text { (dp) }\end{array}$ & $\begin{array}{l}\text { M } \\
(\mathrm{dp})\end{array}$ & $\begin{array}{l}\text { M } \\
\text { (dp) }\end{array}$ & $\begin{array}{l}\text { M } \\
(\mathrm{dp})\end{array}$ \\
\hline Emoções positivas supervisor & $\begin{array}{l}2,72 \\
(0,40)\end{array}$ & $\begin{array}{l}2,51 \\
(0,47)\end{array}$ & $\begin{array}{l}3,04 \\
(0,54)\end{array}$ & $\begin{array}{l}2,82 \\
(0,51)\end{array}$ \\
\hline Emoções positivas empregado & $\begin{array}{l}2,15 \\
(0,40)\end{array}$ & $\begin{array}{l}2,09 \\
(0,43)\end{array}$ & $\begin{array}{l}2,50 \\
(0,51)\end{array}$ & $\begin{array}{l}2,29 \\
(0,49)\end{array}$ \\
\hline Emoções negativas supervisor & $\begin{array}{l}1,98 \\
(0,41)\end{array}$ & $\begin{array}{l}1,95 \\
(0,50)\end{array}$ & $\begin{array}{l}1,92 \\
(0,48)\end{array}$ & $\begin{array}{l}1,95 \\
(0,45)\end{array}$ \\
\hline Emoções negativas empregado & $\begin{array}{l}2,18 \\
(0,42)\end{array}$ & $\begin{array}{l}1,98 \\
(0,42)\end{array}$ & $\begin{array}{l}2,13 \\
(0,46)\end{array}$ & $\begin{array}{l}2,13 \\
(0,44)\end{array}$ \\
\hline
\end{tabular}

"A escala variava de 1 a 4. 
Ao se compararem as médias das atribuições, identificaram-se diferenças significativas entre países. Apesar de serem atribuídas mais emoções positivas ao supervisor que ao empregado nas três nacionalidades, os brasileiros são os que avaliam mais positivamente $o$ supervisor $(M=3,04, d p=0,54, p<.001)$ e o empregado $(M=2,50, d p=0,51, p<.001)$. Mas, em relação às emoções negativas, não houve diferença significativa de atribuição entre países, tanto para supervisor como para empregado. Em poucas palavras, nos três países são atribuídos mais afetos positivos ao supervisor que ao empregado, como se a hierarquia de status estivesse relacionada à hierarquia de afetos. A identificação com o supervisor parece ser mais visível no Brasil do que na Espanha e na Inglaterra. É provável que o processo de socialização para o trabalho de cada país explique tais diferenças. Será que os brasileiros estariam mais identificados com as posições de liderança e chefia? A pesquisa não oferece suporte que nos permita afirmar com segurança.

A Figura 1 resume os intervalos de confiança das atribuições dos participantes dos três países para ambos os atores e ajuda a visualizar as diferenças de atribuição entre eles. O que é digno de nota é que são atribuídas mais emoções positivas do que negativas ao supervisor em todos os três países. A tendência a atribuir-se mais emoções positivas que negativas aos atores em interação de trabalho mantém-se entre os participantes brasileiros e ingleses, mas não entre os espanhóis, que julgaram que o empregado vivencia mais emoções negativas $(M=2,18$, $\mathrm{dp}=0,42, \mathrm{p}<.001)$ que positivas $(\mathrm{M}=2,15, \mathrm{dp}=0,40, \mathrm{p}<.001)$. Contudo, essa tendência é mais marcante no Brasil, onde a discrepância entre as médias de supervisor e empregado é maior. Isso pode ser um sinal de haver no Brasil maior identificação com o supervisor, o que faria com que ele fosse percebido como alguém que vivencia mais emoções positivas, distintamente do empregado que estaria mais desconfortável, inseguro, triste e temeroso na interação.

Figura 1: Intervalo de confiança das médias de emoções positivas e negativas por país

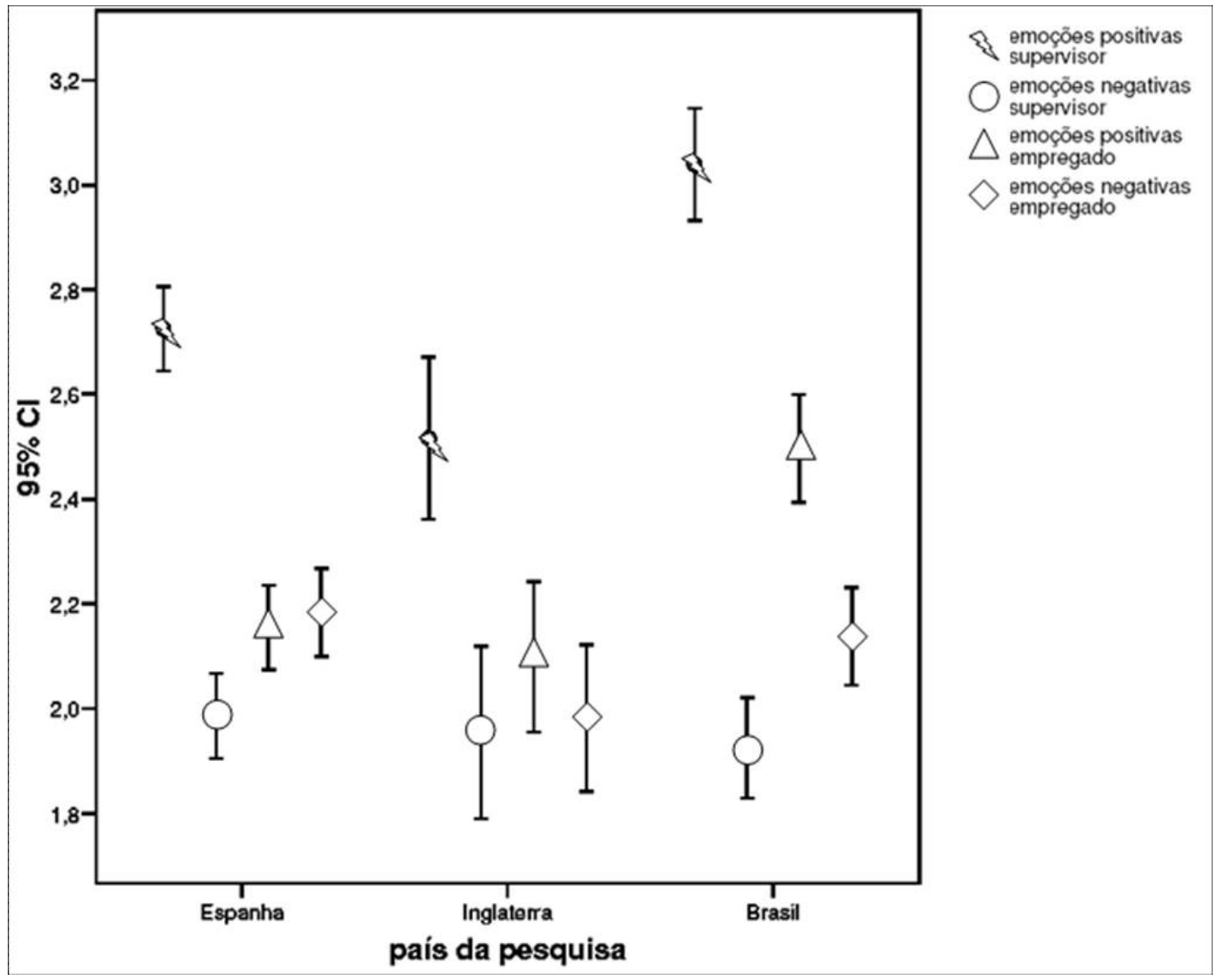


A Inglaterra foi o país com maior variedade de respostas para a mesma emoção - o que pode ser justificado, em parte, pelo tamanho reduzido da amostra. A Espanha, ao contrário, teve a menor amplitude, sinalizando haver maior consenso. Em relação às emoções negativas, houve menor diferença de respostas entre os países, se comparadas com as emoções positivas, mas é importante notar que as emoções positivas do supervisor apresentaram maior variação.

Uma das conclusões possíveis para esse resultado é que as interações entre supervisores e empregados são percebidas em duas perspectivas. $O$ fato de as atribuições de emoções positivas prevalecerem sobre as negativas, para ambos os atores, sugere que a interação de trabalho não é avaliada como conflituosa ou geradora de tensão. Todavia, a maior intensidade de atribuições de emoções positivas para supervisores (médias mais elevadas) que para os empregados permite inferir que, apesar da percepção de uma relação harmoniosa, identificamse diferenças de poder entre os dois atores.

Embora haja uma tendência geral claramente demarcada pelas atribuições positivas a supervisores e empregados, a experiência de trabalho em cada país parece ser uma variável importante. O resultado das atribuições coloca em posições distintas o Brasil, a Espanha e a Inglaterra e aponta a necessidade de as diferenças culturais serem mais bem exploradas em pesquisas futuras, inclusive porque, em estudos anteriores comparando Brasil e Espanha foi identificada mais empatia (atribuições de mais emoções positivas ao empregado) para com o empregado, o que não se confirmou na pesquisa atual. Afinal, o que há no processo de socialização de Brasil, Espanha e Inglaterra que faz com que, apesar de esses países terem internalizado uma hierarquia atrelada à atribuição de afetos positivos e negativos, tal processo seja percebido de modo diferenciado? A pesquisa aqui desenvolvida não explorou em detalhes essas diferenças culturais, os resultados apenas sugerem a necessidade de aprofundar os estudos nessa direção.

\section{Qualidade da interação entre supervisor e empregado}

O segundo item do questionário compreendia vinte e sete estados afetivos, que foram reunidos em dois grupos para a análise: emoções e sentimentos positivos, que contribuiriam para que a relação entre supervisor e empregado fosse percebida como harmoniosa ou de boa qualidade; e os estados afetivos negativos, que contribuiriam para que a interação entre supervisor e empregado fosse percebida como tensa e conflituosa.

No Quadro 3, essas atribuições foram divididas em dois grupos, um com aquelas que sinalizam boa qualidade da interação, e outro com as que indicavam a má qualidade da interação. 
Quadro 3: Percepção da qualidade da interação entre supervisor e empregado da amostra total

\begin{tabular}{|c|c|c|c|c|c|c|}
\hline & Qualificadores & $\begin{array}{l}\text { Não } \\
(f)\end{array}$ & $\begin{array}{l}\text { Supervisor } \\
\text { (f) }\end{array}$ & $\begin{array}{l}\text { Empregado } \\
\text { (f) }\end{array}$ & Ambos (f) & Total $(f)$ \\
\hline $\begin{array}{l}\text { Interação } \\
\text { Positiva }\end{array}$ & $\begin{array}{l}\text { Amizade } \\
\text { Tolerância } \\
\text { Paciência } \\
\text { Apoio } \\
\text { Boa vontade } \\
\text { Companheirismo } \\
\text { Compromisso } \\
\text { Franqueza } \\
\text { Responsabilidade } \\
\text { Seriedade } \\
\text { Harmonia } \\
\text { Simpatia } \\
\text { Humildade } \\
\text { Pena } \\
\text { Compreensão }\end{array}$ & $\begin{array}{l}823 \\
(24 \%)\end{array}$ & $\begin{array}{l}604 \\
(18 \%)\end{array}$ & $\begin{array}{l}433 \\
(13 \%)\end{array}$ & $\begin{array}{l}1562 \\
(45 \%)\end{array}$ & $\begin{array}{l}3422 \\
(100 \%)\end{array}$ \\
\hline $\begin{array}{l}\text { Interação } \\
\text { Negativa }\end{array}$ & $\begin{array}{l}\text { Dureza } \\
\text { Humilhação } \\
\text { Falta de respeito } \\
\text { Arrogância } \\
\text { Rejeição } \\
\text { Superioridade } \\
\text { Grosseria } \\
\text { Falsidade } \\
\text { Prepotência } \\
\text { Culpa } \\
\text { Raiva } \\
\text { Intimidação }\end{array}$ & $\begin{array}{l}1955 \\
(74 \%)\end{array}$ & $\begin{array}{l}455 \\
(17 \%)\end{array}$ & $\begin{array}{l}147 \\
(6 \%)\end{array}$ & $\begin{array}{l}84 \\
(3 \%)\end{array}$ & $\begin{array}{l}2641 \\
(100 \%)\end{array}$ \\
\hline Total & & $\begin{array}{l}2778 \\
(46 \%)\end{array}$ & $\begin{array}{l}1059 \\
(18 \%)\end{array}$ & $\begin{array}{l}580 \\
(9 \%)\end{array}$ & $\begin{array}{l}1646 \\
(27 \%)\end{array}$ & $\begin{array}{l}6063 \\
(100 \%)\end{array}$ \\
\hline
\end{tabular}

(f) frequência de referências a emoções positivas e negativas na interação entre supervisor e empregado.

A partir dos dados do Quadro 3, conclui-se que, para os participantes, ambos os atores interagem positivamente, ou seja, apresentam comportamentos que favorecem a harmonia na relação. A maioria (74\%) dos participantes não conseguiu identificar aspectos negativos da interação entre supervisor e empregado, o que mantém consistência com os resultados da análise das emoções atribuídas a cada um dos atores em separado, objeto de análise da seção anterior. Em contrapartida, 17\% afirmaram que a interação negativa, quando ocorre, deve-se ao comportamento do supervisor, o que permite inferir que as pessoas creem que a responsabilidade pela qualidade da interação depende de quem ocupa uma posição de liderança. Esse resultado é de grande importância para os estudos de gestão, visto que eles indicam que a percepção de hierarquia na relação de supervisores e empregados está atrelada à imputação de maior responsabilidade ao supervisor para assegurar a qualidade das relações no trabalho. E isso parece ser independente de diferenças culturais ou de nacionalidade. É bem verdade que esses resultados compararam países distintos, que tinham em comum sua raiz na cultura ocidental. No entanto, não se pode afirmar que os resultados seriam os mesmos se a comparação fosse feita com um país do oriente.

Dos 3422 qualificadores positivos atribuídos à interação dos dois atores, aqueles que os participantes julgaram ser tanto do supervisor quanto do empregado foram os seguintes: paciência $(f=119)$, responsabilidade $(f=163)$, compromisso $(f=137)$ e companheirismo 
$(f=115)$. Isso fortalece os argumentos ora apresentados de que a interação apresentada no vídeo foi percebida como positiva, mas também sinaliza que o fato de se estar no contexto de trabalho faz emergir aspectos da postura e do engajamento profissional. Das 224 atribuições, 152 (67\%) atribuíam seriedade na interação tanto para o supervisor quanto para o empregado. Isso mostra que, mesmo que o supervisor seja percebido como o responsável pela qualidade da relação estabelecida, percebe-se seriedade no contexto de trabalho.

Do total de 3422 atribuições positivas à interação, 157 (4,5\%) participantes julgaram que o supervisor deu apoio ao empregado, ao passo que $111(3,2 \%)$ disseram que a atitude do empregado foi de humildade. Isso fortalece a crença na polarização dos papéis de supervisor e empregado, ao mesmo tempo em que reafirma a responsabilidade que o supervisor tem na manutenção da harmonia das relações de trabalho.

Entre as 2641 atribuições negativas para a interação, as que mais se destacaram foram: dureza $(f=96,3,6 \%)$ e superioridade $(f=126,4,7 \%)$. Das 96 pessoas que identificaram dureza na interação, $79(83 \%)$ a associam ao supervisor, ao passo que somente quatro (4\%) julgaram que ela estava associada ao empregado, e 13 (13,54\%) que estava presente em ambos. Das 126 pessoas que atribuíram superioridade na interação, 120 (95\%) disseram estar associadas ao supervisor e $6(5 \%)$ a ambos. No caso específico da superioridade, vale ressaltar que esse atributo não foi associado nenhuma vez ao empregado. Um estado afetivo fortemente relacionado ao empregado foi culpa. Das 83 atribuições desse sentimento na interação, 74 (88\%) foram associadas ao empregado, e somente cinco (6\%) estiveram associadas ao supervisor ou a ambos $(f=4,4,8 \%)$.

Uma das conclusões é que a interação de trabalho é predominantemente avaliada positivamente, sinalizando haver paciência, responsabilidade, compromisso e companheirismo. Não se pode ignorar, todavia, que dureza e superioridade, por exemplo, foram atribuídas mais aos supervisores, indicando que eles são avaliados como os responsáveis pela qualidade da interação no trabalho.

Com o objetivo de testar a força de associação entre as variáveis país, condição experimental e sexo (variável independente - qualidade da interação entre supervisor e empregado), foi realizada uma ANOVA fatorial e constatou-se diferença estatística F $(5,204$; $2,836, \mathrm{p}<.05$ ). No Brasil, a interação entre duas mulheres (supervisora e empregada) (SMEM) teve os escores mais elevados de afetos positivos presentes na interação, sendo que a mulher $\left(M=42,58^{*}\right)^{7}$ avalia ainda mais positivamente essa relação que os homens $(M=39,54 *) . \mathrm{Na}$ Inglaterra, a interação entre uma supervisora mulher e um empregado homem (SMEH) foi a que apresentou escores mais elevados de afetos positivos na interação, mas os homens $(\mathrm{M}=56,00 *)$ avaliaram mais positivamente que as mulheres $(41,14 *)$. Na Espanha, a interação de maior escore foi a estabelecida entre supervisor homem e empregada mulher (SHEM), sendo que as mulheres $\left(M=44,47^{*}\right)$ atribuíram mais afetos positivos que os homens $(M=39,00 *)$. Em outras palavras, a relação de trabalho mais harmoniosa no Brasil é a percebida entre duas mulheres (principalmente avaliada por mulheres), na Espanha, entre um homem e uma mulher, ocupando ele o cargo de chefia (principalmente na avaliação de mulheres) e na Inglaterra, entre uma mulher e um homem, sendo ela a chefe (principalmente na avaliação de homens). Sem dúvida, diferenças que precisam ser mais bem exploradas.

No geral, ou seja, desconsiderando as condições experimentais, já apontadas acima, os brasileiros foram os que mais atribuíram afetos positivos na interação entre o supervisor e o empregado $\left(M=41,83^{*}\right)$, seguido dos participantes da Inglaterra $(M=41,32 *)$ e dos da Espanha $\left(\mathrm{M}=40,07^{*}\right)$. Os homens brasileiros $\left(\mathrm{M}=43,19^{*}\right)$ atribuíram mais afetos positivos à interação entre supervisor e empregado do que as mulheres $\left(M=41,24^{*}\right)$. Na Inglaterra e na Espanha, as mulheres atribuíram afetos mais positivos à interação que os homens. Na Inglaterra

7 Esse índice representa a soma dos estados afetivos positivos atribuídos à interação. O valor máximo é 60 . Todas as médias em que aparece o sinal de asterisco foram calculadas com base nesse índice. 
a média das mulheres para atribuição de afetos positivos à interação foi $M=41,44^{*}$ contra $M=40,67 *$ dos homens. Na Espanha a média feminina foi $M=40,68 *$ contra $M=39,15^{*}$ da masculina.

Esses resultados permitem concluir que as experiências de trabalho e as informações sobre o status e sexo dos atores repercutem de modo distinto para homens e mulheres de diferentes países.

\section{A escolha e a caracterização das expressões emocionais de supervisores e empregados}

Quanto à segunda parte do questionário, referente à escolha da imagem das emoções básicas representativas dos atores, 219 pessoas da amostra total $(n=238)$ responderam ao item referente ao supervisor e 221 ao item relativo ao empregado. Acredita-se que isso talvez tenha ocorrido pelo fato de a questão não ter sido bem entendida, ou seja, os participantes não perceberam que era solicitado, além de assinalaram o vídeo com a expressão emocional mais representativa do estado emocional do supervisor e do empregado, que descrevessem no espaço indicado no questionário de resposta que emoção estava sendo ali representada.

Nos Quadros 4 e 5, encontra-se a distribuição de frequência das escolhas por país de cada uma das cinco expressões emocionais apresentadas em vídeo, primeiro para o supervisor e depois para o empregado. Eles apontam resultados congruentes com os da pesquisa anterior em que a imagem da tristeza foi a mais escolhida tanto para supervisor quanto para o empregado. Ao ser observada a ordem de escolha das imagens para cada ator, nota-se que a única diferença diz respeito às imagens de contentamento e medo. Os participantes tenderam a atribuir mais medo que contentamento ao empregado, ao passo que, em relação ao supervisor, essa ordem se inverte.

Quadro 4: Distribuição da escolha das imagens do supervisor apresentadas em vídeo

\begin{tabular}{|l|l|l|l|l|}
\hline \multirow{2}{*}{ Imagem } & \multicolumn{3}{|c|}{ País $f(\%)$} & \multirow{2}{*}{ Total $f(\%)$} \\
\cline { 2 - 4 } & Espanha & Inglaterra & Brasil & \\
\hline 1) Contentamento & $16(17,7 \%)$ & $6(17,2 \%)$ & $26(27,6 \%)$ & $48(21,9 \%)$ \\
\hline 2) Tristeza & $36(40 \%)$ & $18(51,4 \%)$ & $46(49 \%)$ & $100(45,7 \%)$ \\
\hline 3) Raiva & $17(18,9 \%)$ & $6(17,1 \%)$ & $5(5,3 \%)$ & $28(12,8 \%)$ \\
\hline 4) Asco & $3(3,3 \%)$ & $1(2,9 \%)$ & $6(6,4 \%)$ & $10(4,6 \%)$ \\
\hline 5) Medo & $18(20,1 \%)$ & $4(11,4 \%)$ & $11(11,7 \%)$ & $33(15 \%)$ \\
\hline Total & $90(100 \%)$ & $35(100 \%)$ & $94(100 \%)$ & $219(100 \%)$ \\
\hline
\end{tabular}

Quadro 5: Distribuição da escolha das imagens do empregado apresentadas em vídeo

\begin{tabular}{|l|l|l|l|l|}
\hline \multirow{2}{*}{ Imagem } & \multicolumn{3}{|c|}{ País $f(\%)$} & \multirow{2}{*}{ Total $f(\%)$} \\
\cline { 2 - 4 } & Espanha & Inglaterra & Brasil & \\
\hline 1) Contentamento & $14(15,2 \%)$ & $4(11,4 \%)$ & $38(40,4 \%)$ & $56(25,3 \%)$ \\
\hline 2) Tristeza & $38(41,4 \%)$ & $7(20 \%)$ & $30(32 \%)$ & $75(34 \%)$ \\
\hline 3) Raiva & $10(10,8 \%)$ & $9(25,7 \%)$ & $8(8,5 \%)$ & $27(12,2 \%)$ \\
\hline 4) Asco & $4(4,3 \%)$ & $0(0 \%)$ & $2(2,1 \%)$ & $6(2,7 \%)$ \\
\hline 5) Medo & $26(28,3 \%)$ & $15(42,9 \%)$ & $16(17 \%)$ & $57(25,8 \%)$ \\
\hline Total & $92(100 \%)$ & $35(100 \%)$ & $94(100 \%)$ & $221(100 \%)$ \\
\hline
\end{tabular}


A imagem de tristeza foi a mais escolhida por todos os países. No entanto, a ela foram atribuídas emoções mais positivas, como seriedade e responsabilidade, do que negativas. Seriedade foi a expressão emocional mais atribuída à imagem de tristeza, embora ela seja desigual para supervisores $(n=47)$ e empregados $(n=25)$. $O$ fato de a foto que pretendia expressar tristeza ser vista como de seriedade indica que essa expressão é ambígua, e o fato de ela significar responsabilidade (evitando-se a expressão de sentimentos pessoais) revela que os aspectos racionais são mais valorizados nas interações de trabalho que os aspectos emocionais.

A imagem de medo também se revelou imprecisa na caracterização feita pelos participantes, ora associada à atenção, ao encantamento e ao otimismo, ora associada à ansiedade, à insatisfação e à dúvida. Em nove casos, no entanto, a imagem de medo esteve associada ao próprio medo, mas somente para o empregado.

Nojo e raiva foram imagens menos escolhidas para representar os estados afetivos dos atores, e, nos casos em que apareceram, estiveram fortemente associadas a atribuições negativas. Asco esteve associado à desconfiança, desprezo e indiferença, por exemplo. Raiva foi associada a aborrecimento, insatisfação e ansiedade. Além disso, apenas quatro das 55 respostas para a imagem de raiva identificavam raiva propriamente dita na expressão facial do ator.

Nas Figuras 2 e 3 encontram-se especificadas as emoções atribuídas pelos participantes às imagens escolhidas para supervisor e empregado, respectivamente, distribuídas por país.

Figura 2: Emoções atribuídas às imagens escolhidas para supervisor distribuídas por país

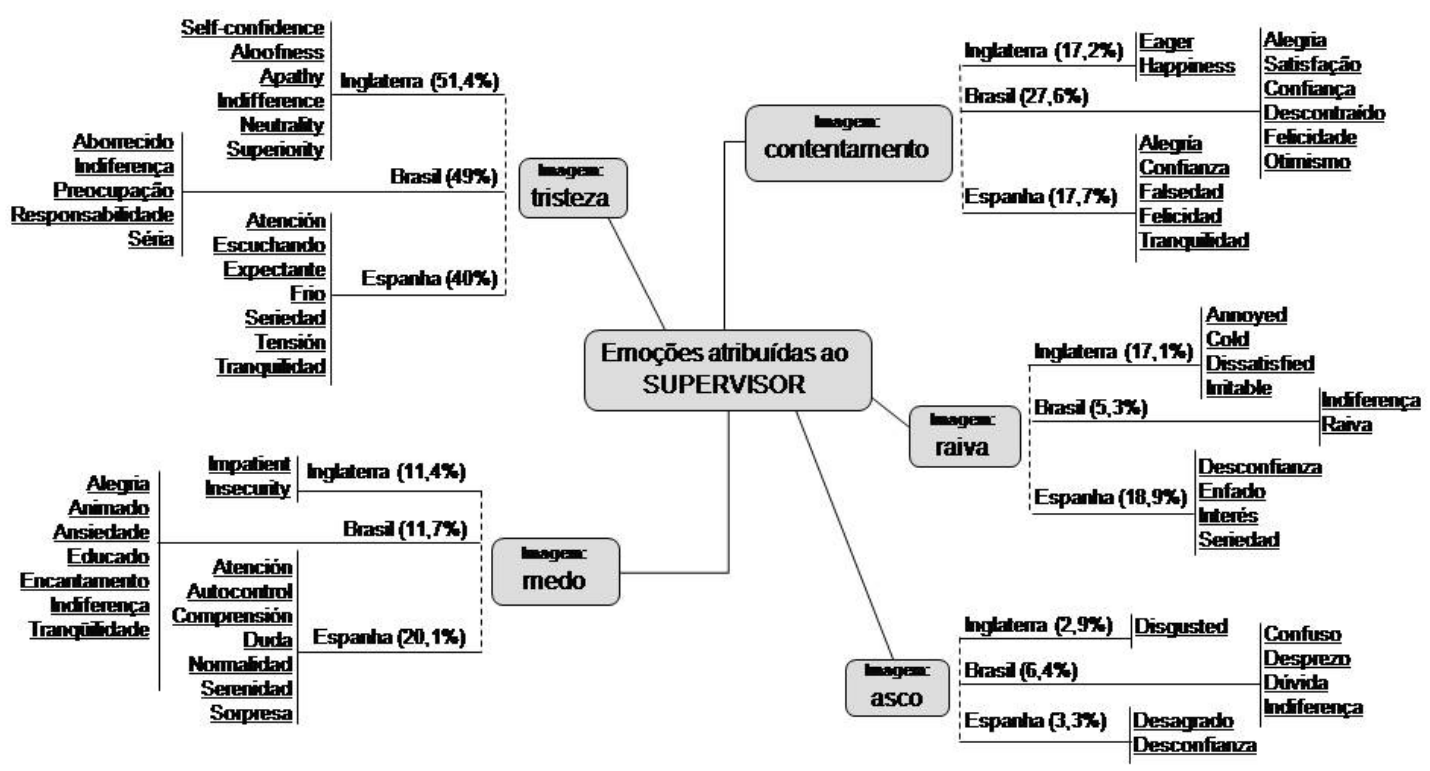


Figura 3: Emoções atribuídas às imagens escolhidas para empregado distribuídas por país

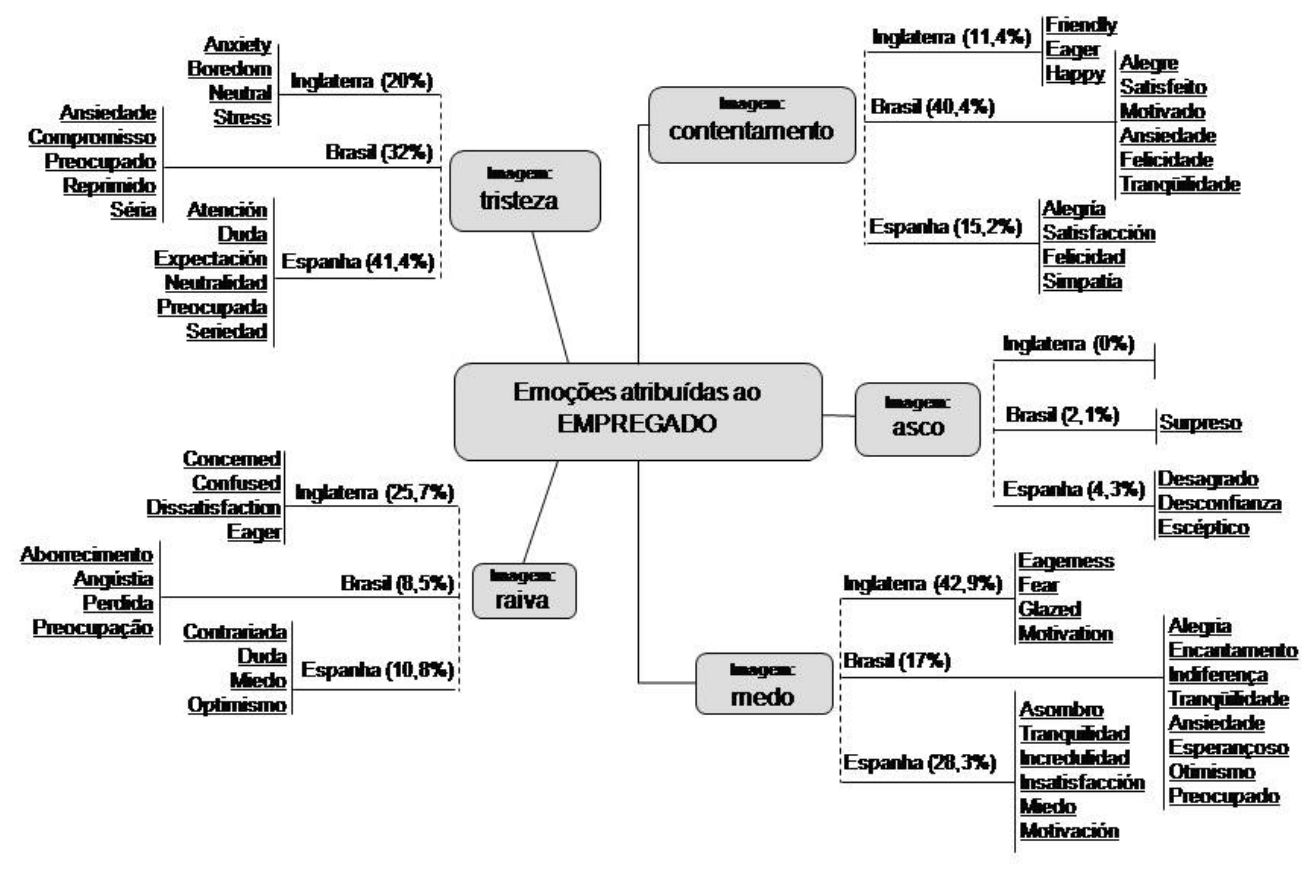

Em relação às diferenças e semelhanças entre os países pesquisados, observou-se que, em todos eles a imagem de tristeza foi a mais assinalada para o supervisor, sendo que, no Brasil, essa tendência ficou mais evidente. A escolha da imagem de tristeza, entretanto, não parece significar que as pessoas atribuam emoções negativas aos atores. Na Espanha, por exemplo, as emoções negativas atribuídas à imagem do supervisor - preocupação e tensão -, foram relacionadas à responsabilidade de estar na posição de líder, o que pode ser percebido como positivo. Na Inglaterra, houve predomínio de atribuições negativas à imagem de tristeza, sendo que a única atribuição positiva para a imagem - self-confidence -, apareceu como traço do supervisor.

No caso do empregado, a imagem de tristeza foi a mais escolhida pelos espanhóis $(n=38)$, ainda que no Brasil essa imagem também tenha sido bastante escolhida $(n=30)$, perdendo apenas para contentamento $(\mathrm{n}=38)$. Entretanto, nos dois países, a imagem da tristeza não foi interpretada como algo negativo, pois, na maioria dos casos ficou associada à racionalidade e à imparcialidade, manifestações esperadas nas relações entre supervisores e empregados (Fineman, 1993). Espanhóis e brasileiros atribuíram mais fortemente a expressão de seriedade à imagem de tristeza e interpretaram tal imagem como um atributo predominantemente do supervisor $(66,6 \%$ e $50 \%$, respectivamente para espanhóis e brasileiros), o que não ocorreu com os ingleses (0\%). A rigor, não temos explicação clara para esses resultados, mas acreditamos que problemas quanto ao tamanho da amostra tenham que ser considerados.

A imagem de contentamento, por sua vez, parece não gerar dúvidas em quem a escolhe, e esteve fortemente associada às emoções positivas, como, por exemplo, alegria, felicidade, otimismo, satisfação, realização, autoconfiança e bom humor.

Os dados apresentados permitem inferir que uma mesma imagem, que aparentemente pretende expressar uma emoção básica, pode estar associada a significados diversos, a depender do contexto em que ela é interpretada. É oportuno lembrar que as imagens eram apresentadas 
sem nenhum rótulo que as descrevesse, exatamente para capturar o processo atribuicional. A interação no trabalho motivou a associação entre a imagem de tristeza e a seriedade e responsabilidade, expressões previsíveis no ambiente de trabalho. O medo, por sua vez, foi a segunda expressão emocional mais escolhida para os empregados, o que não aconteceu com o supervisor. Tal fato sinaliza que, a despeito das diferenças entre os países e de a interação ser percebida como amigável em todos eles, o empregado é avaliado como alguém que possui desvantagem em relação ao supervisor.

\section{Conclusões}

A primeira questão de pesquisa teve como foco estudar se o resultado encontrado em pesquisa anterior, realizada em 2006, manter-se-ia (Gondim, Lima \& Alvaro, 2006). Ou seja, se, a despeito do país onde foram coletados os dados, seriam atribuídas mais emoções positivas ao supervisor que ao empregado sinalizando que para além das supostas diferenças culturais a hierarquia nas interações de trabalho está relacionada com a hierarquia de afetos, fazendo com que o supervisor seja percebido como esboçando mais afetos positivos que os empregados. Em outras palavras, o supervisor encontra-se mais à vontade em seu papel do que o empregado. A análise dos dados responde afirmativamente a essa indagação, pois, embora os afetos positivos para ambos os atores (supervisor e empregado) tenham prevalecido nas relações de trabalho, há uma tendência, nos três países, de se atribuírem mais intensamente emoções positivas ao supervisor. Em relação ao empregado, os espanhóis se diferiram dos brasileiros e ingleses ao atribuir mais emoções negativas a este ator que os demais, resultado contrário aos achados de pesquisas anteriores que apontaram tendência de os espanhóis serem mais empáticos (atribuírem mais afetos positivos) com os empregados.

A segunda questão procurou investigar se a experiência de trabalho em cada país influenciava as atribuições de emoções a supervisores e empregado. A pesquisa não ofereceu, no entanto, respostas satisfatórias a essa questão, uma vez que a maioria dos participantes dos três países revelou possuir experiência profissional como supervisor e como empregado, o que dificultou a comparação entre os participantes, dentro do mesmo país e entre eles. Ou seja, para explorar as diferenças culturais tornam-se necessários mais estudos.

A terceira questão teve como foco avaliar se as informações do sexo e do status (poder) profissional (supervisor ou empregado) influenciavam nas atribuições aos atores. A comparação dos resultados gerais dos três países forneceu fortes argumentos a favor das dicas de contexto, conforme estudos de Algoe et al. (2000), sobretudo das informações sobre status e poder, indicando que essas variáveis exercem forte influência na atribuição de emoções em contextos de trabalho, o que também está de acordo com a suposição de Kemper $(1978,2004)$. Além disso, o sexo se mostrou uma variável muito forte nos processos de atribuição, embora em menor grau que as variáveis poder e status.

Há de se considerar, todavia, que uma das principais vias de acesso às emoções alheias é a expressão facial. $\mathrm{O}$ estudo coincide com conclusões anteriores de que a expressão facial das emoções é ambígua e que sua interpretação depende do contexto social da interação (Hess et al., 2004). A ambivalência e ambiguidade também se revelaram na pesquisa, pois a expressão facial de tristeza (supostamente uma emoção negativa) foi a mais escolhida para supervisores e empregados, porém com sentidos diversos. A associação mais forte da tristeza foi com a seriedade, provavelmente porque, nas relações de trabalho, são priorizadas posturas racionais em detrimento das emocionais.

É preciso reconhecer, não obstante, que os resultados ainda são bastante inconclusos. Alguns deles apontam a favor de uma visão compartilhada de relações de trabalho entre países 
de cultura ocidental, que pode ser assim formulada: os supervisores exibem mais afetos positivos que os empregados, embora as relações de trabalho entre supervisores e empregados sejam percebidas como amistosas mais que aversivas. Em contraposição, outros resultados revelam que as diferenças hierárquicas não são ignoradas, o que explica o fato de os afetos negativos serem mais atribuídos ao empregado que ao supervisor. Outro fato curioso é a análise da percepção da qualidade da interação entre supervisores e empregados, pois, quando algo não ia bem, a culpa era atribuída ao supervisor, o que sugere ser dele a responsabilidade pela presença de afetos negativos na interação.

Enfim, a pesquisa concluiu mais a favor das semelhanças entre os países do que de suas diferenças, embora algumas portas tenham sido abertas a exploração, como a percepção das relações mais harmoniosas no trabalho, que foram distintas para os três países.

Ao dirigir a atenção para os limites da pesquisa, torna-se necessário reconhecer que os instrumentos usados na coleta de dados podem ter repercutido nos resultados. A interação exibida nos vídeos foi encenada por atores brasileiros e posteriormente dublada por nativos dos dois outros países pesquisados. Isso pode ter dificultado a identificação dos participantes ingleses e espanhóis, apesar de ambos terem respondido afirmativamente à pergunta sobre a familiaridade com a situação retratada. Essa dificuldade foi maior na Inglaterra, pois a maioria dos participantes era de outras nacionalidades.

Por fim, apesar dos pontos críticos assinalados no parágrafo anterior, estudos sobre as atribuições de afetos se mostram úteis para compreender a qualidade das interações de trabalho. Em tais contextos, apesar de a hierarquia ainda ser bem demarcada, convive-se com mudanças na configuração das interações, visto que, nos últimos anos, houve um crescimento expressivo da mulher em cargos de chefia e supervisão.

Os estudos interculturais também devem ser estimulados por aumentarem a capacidade de se compreender até que ponto as relações sociais de trabalho são generalizadas ou dependem de variáveis culturais. Os resultados do presente estudo sinalizam haver diferenças entre os países na atribuição de emoções e afetos em contextos de trabalho e na percepção da qualidade da relação entre supervisor e empregado. Todavia, tais resultados também indicam de modo claro a importância do líder na manutenção da boa qualidade das interações de trabalho, independentemente do país. Isto fortalece a necessidade de estudos que explorem mais aprofundadamente a interface entre cultura e processos de atribuição de emoções.

\section{Referências}

Algoe, S. B., Buswell, B. N. \& DeLamater, J. D. (2000). Gender and job status as contextual cues for the interpretation of facial expression of emotion. Sex Roles, 42, 183-218.

Barbalet, J. (2002). Emotions and sociology. Oxford: Blackwell.

Bless, H. (2000). The interplay of affect and cognition: the mediating role of general knowledge structures. In J. P. Forgas (Ed.), Feeling and thinking: the role of affect in social cognition (pp. 201-222). Cambridge: University Press.

Brief, A. P. \& Weiss, H. M. (2002). Organizational behavior: affect in the workplace. Annual Review of Psychology, 53, 279-307.

Briner, R. B. (1999). The neglect and importance of emotion at work. European Journal of Work and Organizational Psychology, 8 (3), 323-346.

Brody, L. R. \& Hall, J. A. (1993). Gender and emotion. In M. Lewis \& J. M. Haviland (Eds.), Handbook of emotions (pp. 447-460). New York: Guilford.

Burkitt, I. (2002). Complex emotions: relations, feelings, and images in emotional experience. In J. Barbalet (Ed.), Emotions and sociology (pp. 151-167). Oxford: Blackwell. 
Caroll, J. M. \& Russell, J. A. (1996). Do facial expressions signal specific emotions? Judging emotion from the face in context. Journal of Personality and Social Psychology, 70 (2), 205-218.

Cobêro, C., Primi, R. \& Muni, M. (2006). Inteligência emocional e desempenho no trabalho: um estudo com MSCEIT, BPR-5 e 16PF. Paideia, 16 (35), 337-348

Crittenden, K. S. (1983). Sociological aspects of attribution. Annual Review of Sociology, 9, 425-446.

Davidson, R. J., Scherer, K. R. \& Goldsmith, H. H. (2003). Handbook of affective sciences. England: Oxford University Press.

Eagly, A. H., Mackhijani, M. G. \& Klonsky, B. G. (1992). Gender and evaluation of leaders: a meta analysis. Psychological Bulletin, 111 (1), 3-22.

Ekman, P. (1999). Basic emotions. In T. Dalgleish \& M. Power (Eds.), Handbook of cognition and emotion (pp. $45-$ 60). Sussex: John Wiley \& Sons.

Evans, D. (2003). Emotion: a very short introduction. Oxford: Oxford University Press.

Fineman, S. (1993). Emotion in organization. London: Sage.

Fischer, A. H. \& Manstead, A. S. R. (2000). The relation between gender and emotion in different cultures. In A. H. Fischer (Ed.), Gender and emotion: social psychological perspectives (pp. 71-96). Cambridge: Cambridge University Press.

Forgas, J. P. \& George, J. M. (2001). Affective influences on judgments and behavior in organizations: an information processing perspective. Organizational Behavior and Human Decisions Processes, 86 (1), 3-34.

Gatton, D. S., DuBois, C. L. Z. \& Faley, R. H. (1999). The effects of organizational context on occupational genderstereotyping. Sex Roles, 7 (8), 567-582.

Gondim, S. M. G., Lima, M. E. O. \& Alvaro, J. L. (2006). Gênero e status na atribuição de afetos no trabalho: um estudo intercultural Brasil e Espanha. Revista Psicologia, Organizações e Trabalho, 6, 165-195.

Gondim, S. M. G. \& Siqueira, M. M. M. (2004). Emoções e afetos no trabalho. Em J. Zanelli, J. Borges-Andrade \& A. V. Bastos (Orgs.), Psicologia, organizações e trabalho no Brasil (pp. 207-236). São Paulo: Artmed.

Gondim, S. M. G., Alvaro, J. L., Schweiger Gallo, I., Sá, M. O. \& Rios, M. (2008) O Chefe tem sempre razão? Um estudo intercultural das expectativas sociais em interações de trabalho. Revista Interamericana de Psicologia, 42 (2), 381-389.

Gondim, S. M. G. \& Álvaro, J. L. (2010). Naturaleza y cultura en el estudio de las emociones. Revista Española de Sociología, 13, 31-47.

Grandey, A. A. (2000). Emotion regulation in the workplace: a new way to conceptualize emotional labor. Journal of Occupational Health Psychology, 5, 95-110.

Gray, E. \& Watson, D. (2001). Emotion, mood, and temperament: similarities, differences and a synthesis. In R. L. Payne \& C. L. Cooper (Eds.), Emotions at work: theory, research and applications for management (pp. 21-44). London: John Wiley \& Sons.

Härtel, C. E. J., Zerbe, W. J. \& Ashkanasy, N. M. (2004). What an emotions perspective of organizational behavior offers. In C. E. J. Härtel, W. J. Zerbe \& N. M. Ashkanasy (Eds.), Emotions in organizational behavior (pp. 359-369). New York: Lawrence Erlbaum Associates.

Hess, V. \& Kirouac, G. (2004). Emotion expression in groups. In M. Lewis \& J. M. Haviland-Jones (Eds.), Handbook of emotions. (2⿳亠丷厂 ed., pp. 368-381). New York: Guilford.

Hochschild, A. R. (1979). Emotion work, feeling rules, and social structure. American Journal of Sociology, 85, 551. 575 .

Johnstone, T. \& Scherer, K. L. (2004).Vocal communication of emotion. In M. Lewis \& J. M. Haviland-Jones (Eds.), Handbook of emotions ( $2^{\mathrm{a}}$ ed., pp. 220-235). London: Guilford.

Kemper, T. D. (1978). A social interactional theory of emotions. New York: Wiley.

Kemper, T. D. (2004). Social models in the explanation of emotions. In M. Lewis \& J. M. Haviland- Jones (Eds.), Handbook of emotions (2 ${ }^{\mathrm{a}}$ ed., pp. 45-58). New York: Guilford.

Leary, M. E. (2000). Affect, cognition, and the social emotions. In J. P. Forgas (Ed.), Feeling and thinking: the role of affect in social cognition (pp. 331-356). Cambridge: Cambridge University Press.

Ledoux, J. (1998). The emotional brain the mysterious underpinning of emotional life. New York: Touchstone Rockefeller Center.

Lewis, M. \& Haviland-Jones, J. M. (Eds.). (2004). Handbook of emotion (2ª ed.). New York: Guildford. 
Lima, M. O., Gondim, S. M. G., Santos, I. C. N., Sá, M. O. \& Bonfim, M. C. (2005). Imagens sociais e gênero nas relações de trabalho. Revista Psicologia: Organizações e Trabalho, 5 (1), 71-101.

Oatley, K., Keltner, D. \& Jenkins, J. M. (Eds.). (2007). Understanding emotions (2⿳a ed.). Oxford: Blackwell.

Ortony, A., Clore, G. L. \& Collins, A. (1990) The cognitive structure of emotion. Cambridge: Cambridge University Press.

Parkinson, B., Fisher, A. H. \& Manstead, A. S. R. (2005). Emotion in social relations: cultural, group, and interpersonal processes. New York: Psychology Press.

Plant, E. A., Hyde, J. S., Keltner, D. \& Devine. P. G. (2000). The gender stereotyping of emotions. Psychology of Women Quarterly, 24, 81-92.

Pekrun, R. \& Frese, M. (1992). Emotions in work and achievement. In C. L. Cooper \& I. T. Robertson (Eds.), International Review of Industrial and Organizational Psychology, 7, 153-200.

Phelps, P. (2006). Emotions and cognition: insights from studies of the human amygdale. Annual Review of Psychology, 57, 27-53

Totterdell, P. \& Holman, D. (2003). Emotion regulation in customer service roles: testing a model of emotional labor. Journal of Occupational Health Psychology, 8 (1), 55-73.

Turner, J. H. \& Stets, J. E. (2005). The sociology of emotions. Cambridge: Cambridge University Press.

\section{Endereço para correspondência}

sggondim@ufba.br, sggondim@terra.com.br, jlalvaro@hotmail.com, andre_luna_@hotmail.com, grace.souza@gmail.com, louise_sobral@hotmail.com, claudiacarla22@gmail.com 